\title{
Is tumour size a contraindication to laparoscopic adrenalectomy? Case report
}

\author{
Patryk Fiszer, Sadegh Toutounchi, Ryszard Pogorzelski, Ewa Krajewska, Bartosz Sutkowski, Piotr Gierej, Maciej Skórski
}

Department of General and Thoracic Surgery, Warsaw Medical University, Poland

Videosurgery and Other Miniinvasive Techniques 2012; 7 (2): 144-146 DOI: $10.5114 /$ wiitm.2011.25931

\begin{abstract}
The authors present a case report of a patient with a large, hormonally silent tumour of the right adrenal gland. Due to the patient's numerous strains, the necessity of two gynaecological operations, and treatment of broken bones, adrenalectomy was contraindicated for 2 years. After that time, the size of the tumour reached $18 \mathrm{~cm} \times 12 \mathrm{~cm}$. The patient was selected for laparoscopic adrenalectomy, which was successful. The size of the tumour and performed abdominal surgery did not constitute substantial obstacles, and the less invasive procedure was additionally justified by computed tomography and magnetic resonance imaging results, which demonstrated a benign lesion.
\end{abstract}

Key words: adrenalectomy, laparoscopic adrenalectomy, large adrenal tumours, benign adrenal tumours.

\section{Introduction}

The size of an adrenal tumour is one of the features which affect the performance of laparoscopic adrenalectomy. It is assumed that the diameter of a tumour should not exceed $8 \mathrm{~cm} \mathrm{[1,2].} \mathrm{However,}$ growing experience has allowed even tumours of $9 \mathrm{~cm}$ to be removed successfully by means of laparoscopy, according to some authors [3, 4]. Of decisive importance is the character of the tumour. In the case of benign, hormonally silent tumours, their size does not constitute a contraindication to laparoscopic procedures. This is a case report of laparoscopic adrenalectomy for an $18 \mathrm{~cm} \times 12 \mathrm{~cm}$ tumour.

\section{Case report}

A 62-year-old woman, who has stayed in departments of internal medicine many times, with metabolic syndrome (obesity, hypertension, hypercholesterolaemia), advanced osteoporosis (after bone fractures) and with other burdensome factors, had a large tumour $(11 \mathrm{~cm} \times 10 \mathrm{~cm})$ of the right adrenal gland diagnosed 2 years before. The tumour was assessed as hormonally silent. Some characteristic features in the computed tomography (CT) scan suggested the diagnosis of a myelolipoma. The patient was qualified for surgery, but in the meantime she suffered two bone fractures of the upper extremity. She also underwent two gynaecological operations, one due to a ruptured ovarian cyst and later hysterectomy. The above factors caused a 2-year delay in the tumour treatment. Computed tomography scan performed next revealed an increase of the tumour size up to $18 \mathrm{~cm} \times 12 \mathrm{~cm}$. The patient was selected for the surgical procedure. Due to obesity and other internal features, open conversion of laparoscopic adrenalectomy was taken into consideration. The procedure was performed by 3 surgeons. The patient was placed in the left lateral position and 4 trocars were inserted along the right costal arch through the transperitoneal route: one, $12 \mathrm{~mm}$, for the optics; two, $10 \mathrm{~mm}$, for dissection tools; and one, $5 \mathrm{~mm}$, for 
the liver retractor. A few adhesions that developed after gynaecological operations were observed intraoperatively. They were lysed. Then the dissection of the tumour was started. The course of surgery was surprisingly satisfactory. The view of the surgical field was assessed as satisfactory and certainly better than in the open approach. Finally, after clipping and cutting the right adrenal vein, the adrenal gland was completely dissected. Haemostasis was achieved by a harmonic scalpel and electrocoagulation. The specimen was retrieved via a small, $6-7 \mathrm{~cm}$ laparotomy site connecting the 2 closest incisions for the middle trocars. The extreme ports were used to push the specimen into the created mini-laparotomy site. Being pulled from the outside and pushed from the peritoneal cavity, the specimen was extracted. The patient was released on the $5^{\text {th }}$ postoperational day in a good condition. Histological examination confirmed the CT scan results. The tumour was myelolipoma with ordinary glandular tissue flattened over the surface of the tumour.

\section{Discussion}

Simultaneously with the process of learning, as in the case of any method, indications for laparoscopy have been extended to treat different afflictions, including adrenal tumours. Currently, the majority of authors believe that patients with adrenal tumours whose diameter does not exceed $8 \mathrm{~cm}$ should be selected for laparoscopy [1, 2]. There are, however, clinical studies assessing the usefulness of laparoscopy in treatment of large adrenal tumours, with diameter significantly exceeding $8 \mathrm{~cm}$. Parnaby et al. [5] compared the results of treatment of adrenal tumours, the size of the mass being below and above $6 \mathrm{~cm}$, and obtained similar results in the compared parameters. In this study, the review of the literature presented confirmed the consistency of our results with the results of other authors. According to the consistent opinion of these authors, in the series of patients with tumours larger than $6 \mathrm{~cm}$, open conversion of laparoscopic adrenalectomy occurred much more often due to massive adhesions or infiltration of adjacent structures. Among 39 patients with large adrenal tumour undergoing laparoscopic adrenalectomy, open conversion took place in 5 cases. In the series of patients with tumours smaller than $6 \mathrm{~cm}$, open conversion was required in one case only. Ramacciato et al. [6] assessed the results of laparoscopic surgery on adrenal tumours with diameter larger than $7 \mathrm{~cm}$ in a series of 18 patients, regardless of the primary pathology. In this group, conversion was necessary in 3 cases (16\%), and each time it was due to bleeding from the damaged tumour or surrounding organs. Neoplasms, both primary and secondary, were confirmed in 4 cases, i.e. just above $20 \%$ of patients. The percentage is much lower than in the earlier reports assessing the probability of both primary and secondary neoplasms in large adrenal tumours with diameter exceeding $6 \mathrm{~cm}$ $[7,8]$. This study also concludes that in the case of adrenal neoplasms operated on laparoscopically, the oncological radicality and survival rate are comparable in relation to the open technique. Brix et al. also obtained similar results in adrenocortical carcinoma laparoscopic treatment in comparison to the open procedure. The series consisted of patients with grade 1 and 2 tumours according to WHO which did not exceed $10 \mathrm{~cm}$ in diameter [9]. Gaujoux et al. made an interesting conclusion in their analyses of 462 laparoscopic adrenalectomies. They stated that being over 70, ASA class 3 or higher, obesity (BMI $>35 \mathrm{~kg} / \mathrm{m}^{2}$ ), abdominal or retroperitoneal surgery, or tumours $>6 \mathrm{~cm}$ should not constitute a contraindication for laparoscopic surgery [10]. Our experience, based on 180 laparoscopic adrenalectomies performed in our centre, proves that abdominal surgery does not have to constitute a contraindication to intraperitoneal laparoscopic adrenalectomy. It may be slightly prolonged due to the necessity of prior lysis of adhesions. Taking into account the literature analysed and our own experience, it may be assumed that the only absolute contraindications to laparoscopic adrenalectomy are a large $(>10 \mathrm{~cm})$, malignant lesion or one infiltrating adjacent organs, and also regional lymph node or distant metastases. We believe that qualification of large adrenal masses for laparoscopic surgery should be based on thorough imaging diagnostics performed in order to assess their character and possible infiltration of surrounding organs. On the other hand, the laparoscopic procedure itself for large lesions, especially dissection of the tumour surface and other anatomically significant structures, is in our opinion more comfortable, and the view of the surgical field is better than in the open technique.

The only issue is the extraction of the specimen through the mini-laparotomy site, which in times of aesthetic concerns may be a problem for some patients. For those patients, single incision laparo- 
scopic surgery, which is successfully employed in some centres, may be an appropriate solution [11].

\section{References}

1. Staren ED, Prinz RA. Adrenalectomy in the era of laparoscopy. Surgery 1996; 120: 706-9.

2. Gupta PK, Natarajan B, Pallati PK, et al. Outcomes after laparoscopic adrenalectomy. Surg Endosc 2011; 25: 784-94.

3. Otto M, Dzwonkowski J, Ciąćka T, et al. Laparoscopic adrenalectomy in elderly patients. Videosurgery and Other Miniinvasive Techniques 2006; 2: 54-8.

4. Toutounchi S, Cieśla W, Krajewska E, et al. Laparoscopic enucleation of a single adrenal tumour in a patent suffering from primary hyperaldosteronism. Videosurgery and Other Miniinvasive Techniques 2007; 2: 164-7.

5. Parnaby CN, Chong PS, Chisholm L, et al. The role of laparoscop ic adrenalectomy for adrenal tumours of $6 \mathrm{~cm}$ or greater. Surg Endosc 2008; 22: 617-21.

6. Ramacciato G, Mercantini P, La Tore $M$, et al. Is laparoscopic adrenalectomy safe and effective for adrenal masses larger than $7 \mathrm{~cm}$. Surg Endosc 2008; 22: 516-21.

7. Copeland PM. The incidentally discovered adrenal mass. Ann Intern Med 1983; 98: 940-5.

8. Ross NS, Aron DC. Hormonal evaluation of the patient with an incidentally discovered adrenal mass. N Engl J Med 1990; 323 1401-5.

9. Brix D, Allolio B, Fenske W, et al. Laparoscopic versus open adrenalectomy for adrenocortical carcinoma: surgical and oncologic outcome in 152 patients. Eur Urol 2010; 58: 609-15.

10. Gaujoux S, Bonnet S, Leconte M, et al. Risk factors for conversion and complications after unilateral laparoscopic adrenalectomy. Br J Surg 2011 May 25. DOI: 10.1002/bjs.7558.

11. Łosin M, Czauderna P, Gołębiowski A, et al. Single incision laparoscopic adrenalectomy - initial experience. Videosurgery and Other Miniinvasive Techniques 2010; 5: 104-6. 